\title{
CORELESS TRANSFORMER FOR POWER QUALITY MEASUREMENT AT MEDIUM VOLTAGE LEVEL
}

\author{
Zoran Mitrović, Dušan Čomić, Slobodan Milovančev, Dragan Pejić
}

Original scientific paper Measurement of grid voltage harmonic components is an important part of power quality measurements. Current high voltage transformers with iron core are not linear and cannot easily be used for accurate measurement of "polluted" voltages in wide frequency range. In this paper, design details of a new coreless voltage transformer for power quality measurement are given. As a proof of concept, two transformers, shielded and unshielded, were realized. Measurement results of transformer parameters, results of transformer behaviour simulation and results of transformer linearity measurement are presented. These results show that the proposed transformer can be used for power quality measurement at low and medium voltage levels (up to $35 \mathrm{kV}$ ) with harmonic voltages up to $50^{\text {th }}$ order

Keywords: coreless transformer; measuring transformer; power quality measurement; power system harmonics

\section{Transformator bez jezgre za mjerenje kvalitete električne energije na srednjem naponu}

Mjerenje harmonika u elektrodistributivnoj mreži predstavlja važan dio mjerenja kvalitete električne energije. Suvremeni visokonaponski transformatori sa željeznom jezgrom nisu linearni i ne mogu se lako koristiti za precizno mjerenje izobličenih signala u širokom frekvencijskom opsegu. U ovom članku dani su detalji konstrukcije novog naponskog transformatora bez jezgre za mjerenje kvalitete električne energije. Kao potvrda koncepta izrađena su dva transformatora, s i bez oklopa. Prikazani su rezultati mjerenja parametara transformatora, rezultati simulacije rada transformatora $\mathrm{i}$ rezultati mjerenja linearnosti transformatora. Ovi rezultati pokazuju da se predloženi transformator može koristiti za mjerenje kvalitete električne energije na niskim i srednjim naponskim razinama (do $35 \mathrm{kV}$ ) s harmonijskim sadržajem do 50 -tog reda.

Ključne riječi: harmonici u elektrodistributivnoj mreži; mjerenje kvalitete električne energije; mjerni transformator; transformator bez jezgra

\section{Introduction}

The importance of power quality measurement has been recognized for long time and widely discussed. The impact of power quality on the performance of power electronic devices $[1,2]$ and quality of consumer's life [3] are well known to engineers. New challenges and restrictions are brought to measurements in "polluted"

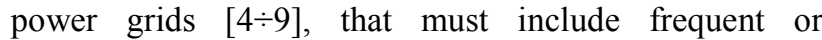
continuous monitoring of the harmonic composition of grid current and voltage $[10,11]$. The importance of power quality measurement arises in open electricity markets [12], where it becomes a significant factor in both technical and financial parameters estimation between the subjects.

For voltage measurement at the mains frequency, measuring transformers with iron core, or voltage dividers (capacitive or resistive) are preferred. Measuring transformers with iron core are non-linear, usually have poor, or, often, undocumented characteristics at higher frequencies and cannot be easily used for measurement of grid harmonic voltages. Voltage dividers have no galvanic isolation and are not suitable for measurements at high voltage levels.

Rogowski coils [13] are used for current measurements for long time $[14,15]$. Output of a Rogowski coil is a voltage proportional to first derivative of a measured current. To obtain the voltage proportional to the current at the primary, we must integrate the output of the Rogowski coil.

For voltage measurements, similar methods have not been widely used. This paper describes a new voltage transducer that is similar by operation to the Rogowski coil. This voltage transducer provides wide frequency range of measured voltage and galvanic isolation, so it can be used to measure voltage harmonics in medium grid voltage (several $\mathrm{kV}$ ) applications.

Recently, a new class of instruments based on stochastic additive $\mathrm{A} / \mathrm{D}$ conversion has been developed. These instruments have high immunity to noise, measure harmonic components (sine and cosine) directly $[16 \div 21]$ and are compatible with both linear and derivative transducers. Instead of high number of voltage samples which demand further data processing, these instruments give amplitudes of two quadrature components per harmonic (sine and cosine component) - for 50 harmonics we have 100 floating point numbers. All data processing is done in frequency domain. For example, integration and derivation for each harmonic component is performed by simply exchanging sine and cosine components and multiplying by -1 (changing the sign) where needed. Good results, obtained when Rogowski coils were used for current measurements with these instruments, inspired the authors to develop a similar transducer for voltage measurement. Further development in the field of coreless transformers and stochastic additive $\mathrm{A} / \mathrm{D}$ converter based instruments is expected in the near future.

In this paper, design details of a new coreless transformer that can be used for various voltage measurements at low and medium voltage levels in power grid, especially for power quality measurement, are presented. This voltage transformer has high linearity, galvanic isolation and wide frequency range. The voltage at the output (secondary) is proportional to first derivative of the voltage at the primary. Similar to the use of a Rogowski coil for current measurement, this voltage has to be integrated to obtain voltage proportional to the input voltage.

As a proof-of-concept, two transformers were realized for laboratory testing, shielded and unshielded 
one, with the same geometry and the other design parameters (wire diameter and number of turns). Calculated values of the electrical parameters were compared to the measured ones. The simulation results and the results of measurement on both transformers are shown in the paper.

\section{Transformer design}

Theoretical background for this transformer is given in [18]. The simplified schematic diagram of the transformer is shown in Fig. 1. The resistor $12 \mathrm{M} \Omega$ is used for the input voltage level of $15 \mathrm{kV}$. For other voltage levels, different high voltage resistors can be used.

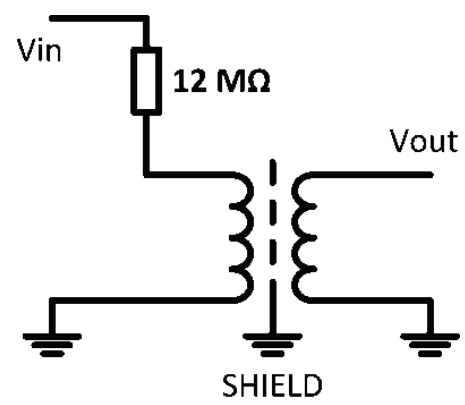

Figure 1 Schematic diagram of the coreless high voltage transformer

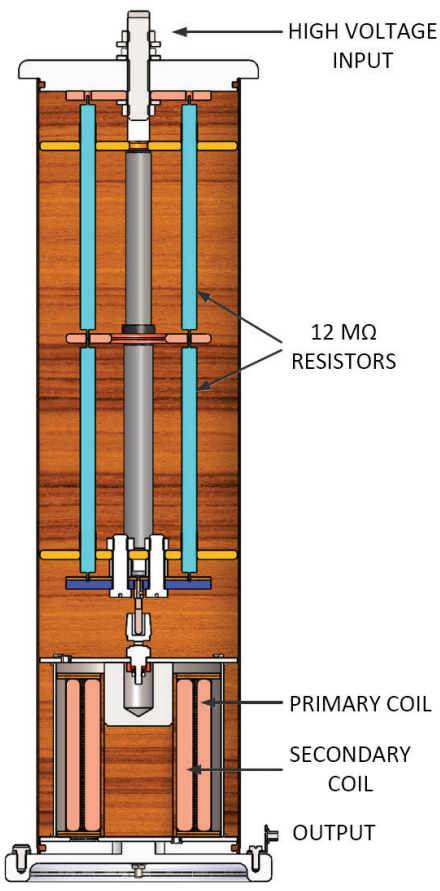

Figure 2 Cross-section of the high voltage coreless transformer prototype

In Fig. 2 a cross-section of the transformer is shown.

The wire diameter of the primary and the secondary coil is $0,16 \mathrm{~mm}$. Both coils have 15000 turns. A grounded copper shield between the primary and the secondary provides faradic isolation and increases safety. One of the realized transformers has an envelope shield. Since coreless transformers amplify higher frequencies due to derivative operation, the purpose of this shield is to prevent the external noise to influence measurements. Measurements of the transformers' parameters show that this shield increases capacitances in the simulation model, which slightly lowers the maximal operating frequency.

Four $12 \mathrm{M} \Omega$ resistors are used to avoid problems due to the resistance voltage coefficient present in high voltage resistors, as well as to lower heating. The resistors are mounted in a detachable housing, and can be easily replaced with resistors of different value to adapt the transformer to different input voltages. The resistors are shown in upper part, and the coreless transformer in bottom part of Fig. 2 .

The transformer is developed primarily as a voltage transducer for a stochastic additive A/D converter-based instrument. Due to that, the output level is in the range of several volts.

In Fig. 3 a photo of the realized transformer is shown.

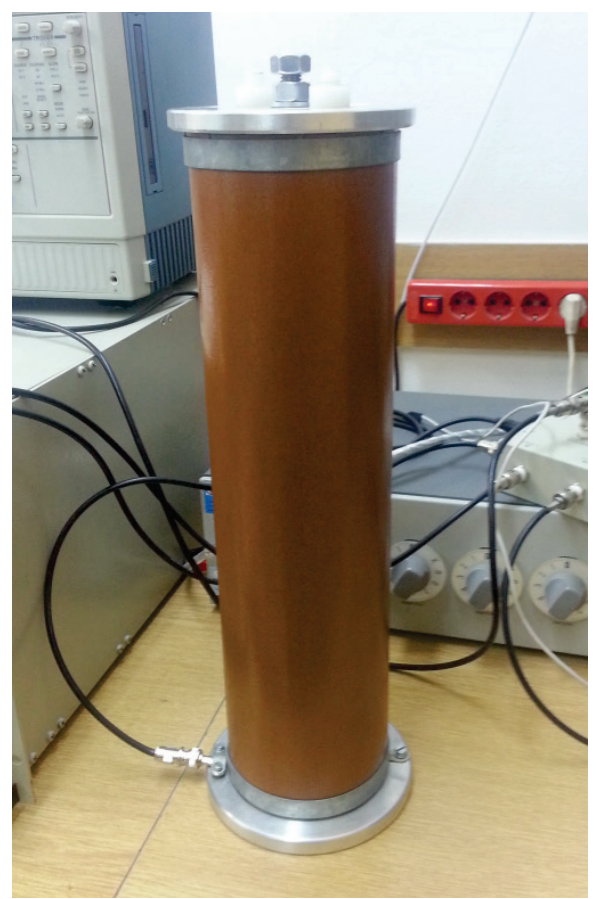

Figure 3 Photo of a high voltage coreless transformer prototype

\section{Transformer parameters}

Measurements were taken on both transformers (unshielded and shielded one) in laboratory, using HIOKI 3511-50 LCR Hi Tester, at $120 \mathrm{~Hz}$ and $1 \mathrm{kHz}$. The results of measurement at $120 \mathrm{~Hz}$ (values of resistance, impedance and inductance in the primary and the secondary, and capacitances between the primary and the secondary, and between the primary and ground and the secondary and ground) are shown in Tab. 1.

Table 1 Electrical parameters of two coreless transformers

\begin{tabular}{|c|c|c|c|}
\hline & & Unshielded & Shielded \\
\hline \multirow{4}{*}{ Primary coil } & $R p$ & $3,03 \mathrm{k} \Omega$ & $3,65 \mathrm{k} \Omega$ \\
\cline { 2 - 4 } & $Z p$ & $7,3 \mathrm{k} \Omega$ & $8,43 \mathrm{k} \Omega$ \\
\cline { 2 - 4 } & $L p$ & $8,8 \mathrm{H}$ & $10,1 \mathrm{H}$ \\
\hline \multirow{4}{*}{ Secondary coil } & $R s$ & $2,04 \mathrm{k} \Omega$ & $2,21 \mathrm{k} \Omega$ \\
\cline { 2 - 4 } & $Z s$ & $4,02 \mathrm{k} \Omega$ & $4,38 \mathrm{k} \Omega$ \\
\cline { 2 - 4 } & $L s$ & $4,54 \mathrm{H}$ & $5,01 \mathrm{H}$ \\
\hline \multirow{3}{*}{$\begin{array}{c}\text { Capacitances } \\
\text { (p - primary, }\end{array}$} & $C p-\mathrm{g}$ & $212,6 \mathrm{pF}$ & $323,5 \mathrm{pF}$ \\
\cline { 2 - 4 } s - secondary, g-ground) & $C p-\mathrm{s}$ & $93,6 \mathrm{pF}$ & $101,5 \mathrm{pF}$ \\
\cline { 2 - 4 } & $C s-\mathrm{g}$ & $131,3 \mathrm{pF}$ & $206,3 \mathrm{pF}$ \\
\hline
\end{tabular}


Some differences in parameters other than capacitances are primarily caused by manufacturing and non-machine wounding process. Similar results were obtained for $1 \mathrm{kHz}$ measurement frequency.

Using the measured parameters, several simulations of transformers' behaviour were made.

\section{Simulation}

The Simulation model of the high voltage coreless transformer is given in Fig. 4. This model describes the behaviour of the transformer very close to the real operation.

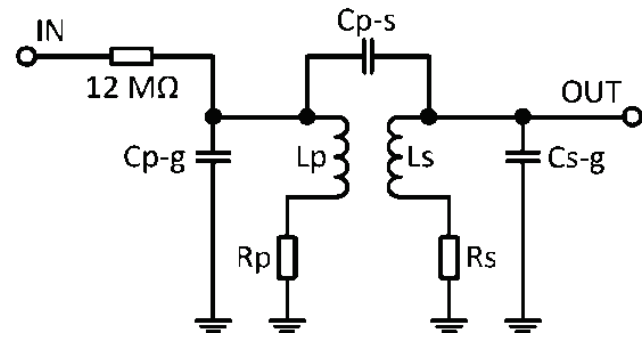

Figure 4 Simulation model of a high voltage coreless transformer

Component values in the simulation model are taken from Tab. 1. The shielded transformer has slightly higher capacitances than the unshielded one. Using parameters for the shielded transformer at low frequencies, the magnitude and the phase of a transfer function plot were constructed. The unshielded transformer has similar transfer function with slightly higher frequency range for derivative operation.

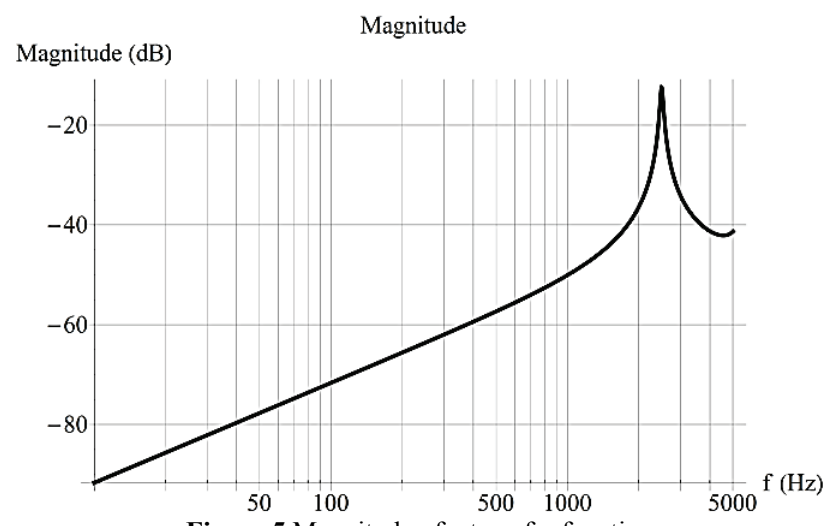

Figure 5 Magnitude of a transfer function

The magnitude of a transfer function plot for shielded transformer is shown in Fig. 5. Again, the unshielded transformer has similar behaviour with a slight shift towards higher frequencies.

From the magnitude of a transfer function plot, it is clearly visible that this transformer has derivative behaviour, similar to Rogowski coil, i.e. that the voltage at the output of this transformer is proportional to first derivative of the input voltage, for frequencies up to approximately $1,5 \mathrm{kHz}$. This proves the theoretical background given in [18]. 6.

The phase of a transfer function plot is shown in Fig.
A derivative mode of operation is often considered as sensitive to noise that can be induced from the environment.
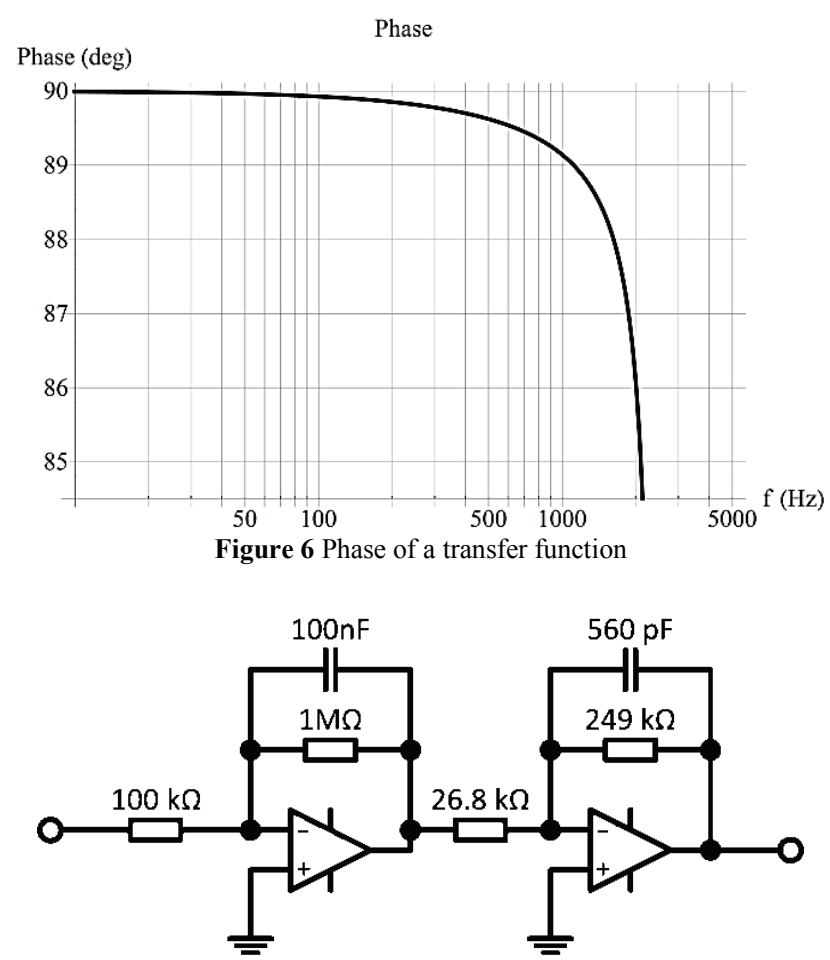

Figure 7 Integrator used for laboratory testing

Several simulations were run to prove that this transformer has high immunity to noisy environment. Two signals, with $8 \%$ THD (maximum allowed by the European norm EN50160 [11]) and with $100 \%$ THD (to check the transformer's behaviour with extremely distorted signals), were presented to the input of the transformer, according to Eq. (1):

$$
\begin{aligned}
& v=V_{1} \sin (\omega t)+V_{2} \sin (2 \omega t)+V_{3} \sin (3 \omega t)+ \\
& V_{4} \sin (4 \omega t)+V_{5} \sin (5 \omega t)+V_{6} \sin (6 \omega t)+V_{7} \sin (7 \omega t)
\end{aligned}
$$

Amplitudes of harmonic components for both test signals (both signals' RMS value was $15 \mathrm{kV}$ ), are given in Tab. 2.

Table 2 Harmonic components of test signals (RMS value $15 \mathrm{kV}$ )

\begin{tabular}{|c|c|c|}
\hline Harmonic order & $8 \% \mathrm{THD} / \mathrm{kV}$ & $100 \% \mathrm{THD} / \mathrm{kV}$ \\
\hline 1 & 21,14 & 14,84 \\
\hline 2 & 0,69 & 6,19 \\
\hline 3 & 0,69 & 6,19 \\
\hline 4 & 0,69 & 6,19 \\
\hline 5 & 0,69 & 6,19 \\
\hline 6 & 0,69 & 6,19 \\
\hline 7 & 0,69 & 6,19 \\
\hline
\end{tabular}

Along with this signal, a noise represented by two FM modulated signals of significant amplitude at several frequencies was injected both in the input signal, and in the secondary coil. The amplitude of noise added to the primary was $1 \mathrm{kV}$, and $1 \mathrm{~V}$ to the secondary. This amount of noise is added to show behaviour of the transformer in extreme conditions, and is far more than can be expected in normal conditions. 
The output of the devices with derivative behaviour cannot be measured directly. The integrator, shown in Fig. 7, was connected to the transformer secondary. This integrator integrates the signal at the secondary and transforms it into a signal which is similar to the input voltage.

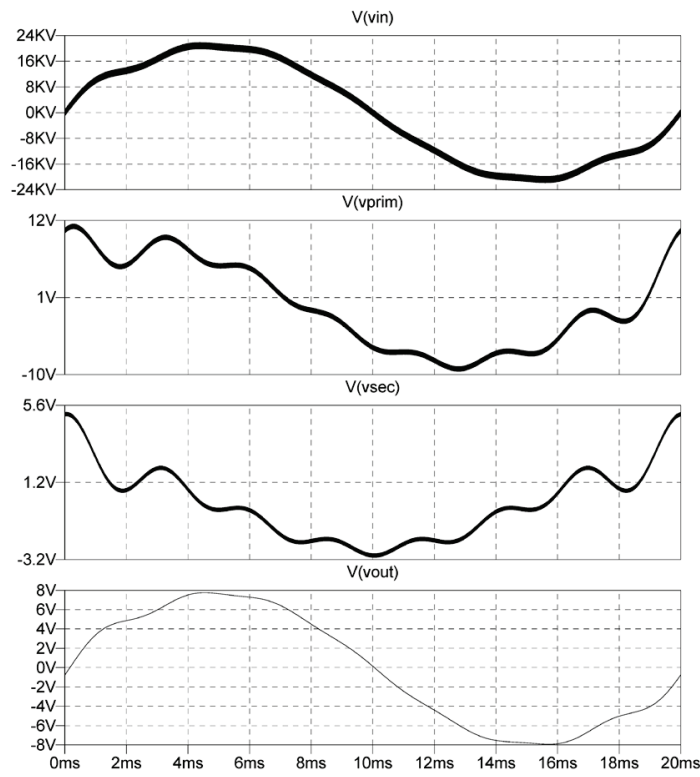

Figure 8 Simulation results for the input voltage with $8 \%$ THD

In Fig. 8 and Fig. 9, voltages at the input, the transformer primary, the transformer secondary and the integrator output are shown (for input signals with RMS value $15 \mathrm{kV}, 8 \%$ THD and $100 \%$ THD respectively).

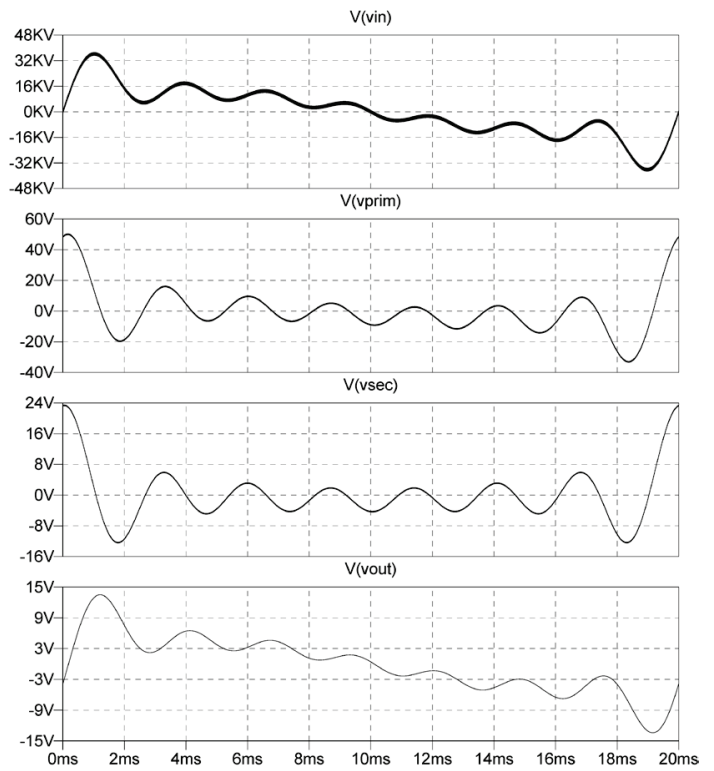

Figure 9 Simulation results for the input voltage with $100 \%$ THD

Thick lines for voltages at the input, the transformer primary and the secondary are in fact noisy signals due to injected noise. The output of the integrator shows a clear signal without noise, similar to the input signal.

The integrator behaves like a low pass filter and cuts off higher frequencies. Frequency components (FFT plot) of the input signal with injected noise at $100 \mathrm{kHz}$ and the output from the integrator are shown in Fig. 10. Again, the FFT plot shows that the integrator attenuates higher frequencies and that the noise components do not have influence on the output signal.

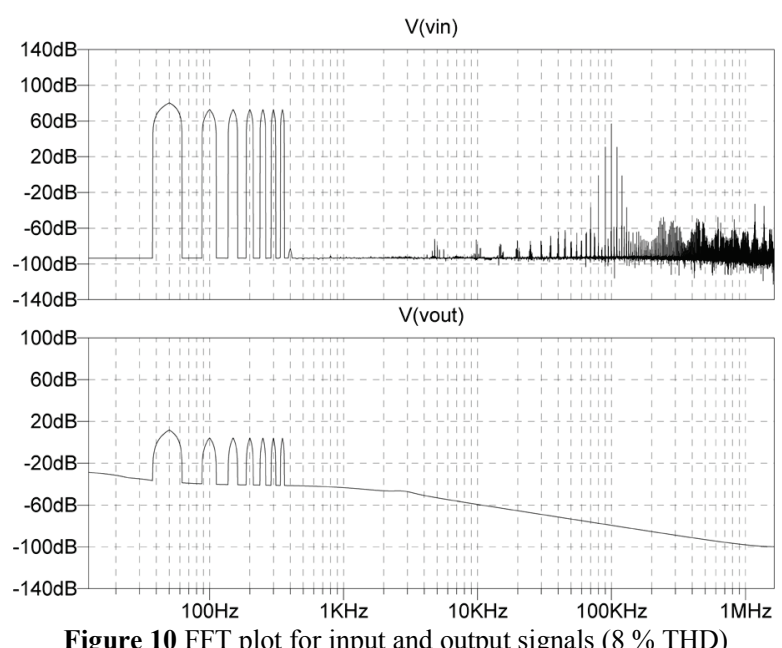

\section{$5 \quad$ Laboratory test results}

For laboratory testing, the coreless transformer was connected to a stable voltage source $[22,23]$ with a step up transformer. The output voltage of the integrator was measured with the system voltmeter HP3458A. Voltage at the transformer's primary was measured using the AC divider and voltmeter Fluke 8846A. Fig. 11 shows the laboratory equipment connected for the experiment.

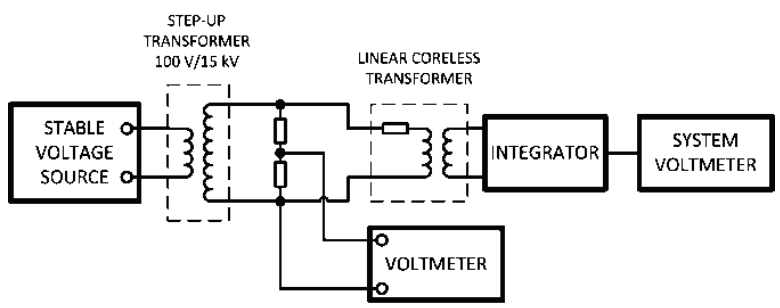

Figure 11 Laboratory test setup

Since the transformer is designed to be linear, without the core which is the main source of nonlinearity, the input test signal can be sinusoidal. Tests at the different frequencies (harmonic multiples of the mains frequency) describe the transformer's behaviour as if the input signal was composite, with several components at different frequencies.

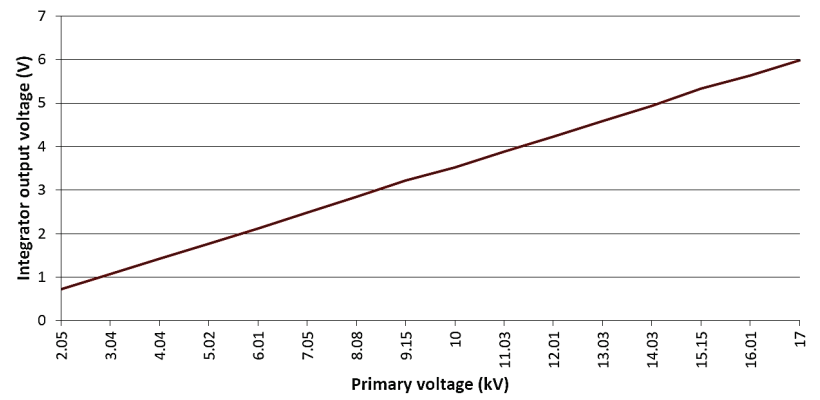

Figure 12 Integrator output voltage for $50 \mathrm{~Hz}$ signal

Several tests at the mains frequency $(50 \mathrm{~Hz})$ and the harmonic multiples $(100 \mathrm{~Hz}, 150 \mathrm{~Hz}$, etc.) and at voltages from $2 \mathrm{kV}$ to $17 \mathrm{kV}$ were performed. Integrator output 
voltage as a function of the high voltage at the input is shown in Fig. 12.

The linearity of measured data is shown as a deviation from the straight line drawn through one measured point, usually for the maximum value. Although not the exact indicator of nonlinearity, this parameter can be useful. Most of transducers are used with amplifiers which can adjust the maximum value, so this parameter can describe the behaviour of the transformer and the amplifier.

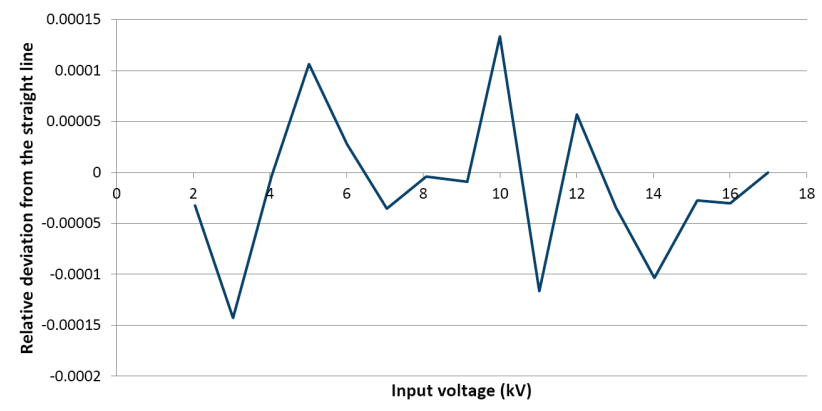

Figure 13 Integrator output voltage deviation from the straight line for $50 \mathrm{~Hz}$ signal

The typical result of measurement, shown as the deviation from the straight line drawn through the measured point at $17 \mathrm{kV}$, is presented in Fig. 13 (the frequency for this test was $50 \mathrm{~Hz}$ ) and in Fig. 14 (the frequency for this test was $150 \mathrm{~Hz}$ ).

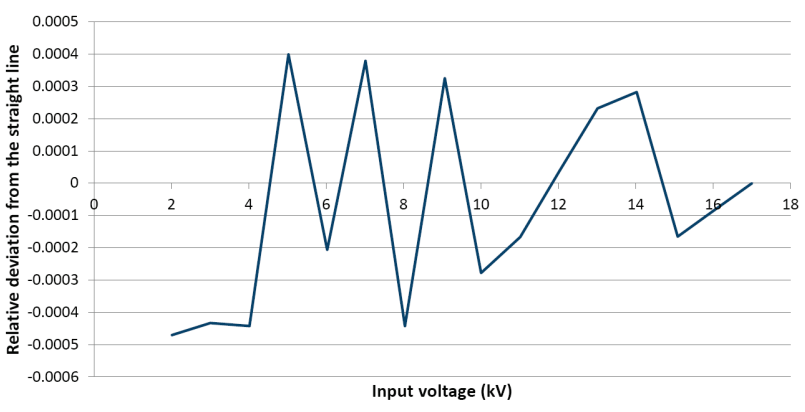

Figure 14 Integrator output voltage deviation from the straight line for $150 \mathrm{~Hz}$ signal

The other results of measurements at different frequencies are very similar to the presented results. This proves high linearity of the coreless transformer. The deviation from the straight line for all harmonic frequencies is in order of $10^{-4}$, which is in the range of good measuring transformers with iron core at the fundamental frequency.

Since this transformer will be used with a new class of instruments based on two-bit A/D converters $[16 \div 21]$, its overall measurement uncertainty will be estimated during detailed validation that follows and included as a (type B) component in combined measurement uncertainty for voltage measurement.

\section{Conclusion}

The design of the linear high voltage coreless transformer for power quality measurement is presented in the paper. The transformer's output voltage is proportional to first derivative of the input voltage. Results of simulation and measurements prove that this transformer is suitable for measurement of voltage harmonic components at low and medium voltage levels. The transformer can be easily adapted to different voltage levels by changing only input resistors. The output voltage level is compatible with electronic instruments, especially with the new class of instruments based on stochastic additive A/D convertors which have input compatible with linear and derivative transducers. An electronic integrator can be attached to the transformer secondary to obtain output voltage proportional to the input voltage.

All simulations and measurements presented in this paper were performed in order to prove the theoretical background for this type of medium voltage transformers and its applicability to power quality measurements and to check how the external noise sources can influence the measurement results.

This transformer can easily be used with the new class of electronic digital instruments, based on stochastic additive $\mathrm{A} / \mathrm{D}$ conversion, for power grid and power quality measurements $[16 \div 21]$. Used with such digital instruments which are compatible with both linear and derivative transducers, the integrator can be omitted and the phase angle, which is inevitably induced by integrators, can be controlled, or even avoided, so this transformer can also be used for active and reactive power measurement.

Transformers presented in this paper can be used with integrators, including the integrator shown in the paper. Used with standard RMS voltmeter, the RMS value of the polluted high voltage signal can be measured.

\section{Acknowledgement}

This work was supported in part by the Ministry of Education, Science and Technological Development of the Republic of Serbia under research grants Nos. TR32019 and III43011 started on 01.01.2011.

\section{References}

[1] Thapar, A.; Saha, T. K.; Zhao, Y. D. Investigation of power quality categorisation and simulating its impact on sensitive electronic equipment. // IEEE Power Engineering Society General Meeting, 6-10 June 2004, IEEE. Vol. 1, (2004), pp. 528-533.

[2] Kovacova, I.; Kovac, D. Inductive Coupling of Power Converter's - EMC. // Acta Polytechnica Hungarica. 6, 2(2009).

[3] Sermon, R. C. An overview of power quality standards and guidelines from the end-user's point-of-view. // Rural Electric Power Conference, 8-10 May 2005. IEEE, (2005), pp. B1/1-B1/5.

[4] Broshi, A. Monitoring power quality beyond EN 50160 and IEC 61000-4-30. // $9^{\text {th }}$ International Conference on Electrical Power Quality and Utilisation (EPQU 2007), 911 October 2007, IEEE. (2007), pp. 1-6. DOI: 10.1109/EPQU.2007.4424114

[5] Kuhlmann, V.; Sinton, A.; Dewe, M.; Arnold, C. Effects of sampling rate and ADC width on the accuracy of amplitude and phase measurements in power-quality monitoring. // IEEE Transactions on Power Delivery. 22, 2(2007), pp. 758-764. DOI: 10.1109/TPWRD.2007.893389

[6] Agrez, D. Estimation and Tracking of the Power Quality Disturbances in the Frequency Domain. // Meas. Sci. Rev. 10, 6(2010), pp. 189-194. DOI: 10.2478/v10048-010-0032-4 
[7] Hribik, J.; Fuchs, P.; Hruškovic, M.; Michálek, R.; Lojko, B. Digital Power and Energy Measurement. // Meas. Sci. Rev. 4, 3(2004).

[8] Petrovic, P. Frequency and Parameter Estimation of MultiSinusoidal Signal. // Meas. Sci. Rev. 12, 5(2012), pp. 175183. DOI: $10.2478 / \mathrm{v} 10048-012-0027-4$

[9] Klaic, Z.; Nikolovski, S.; Kraus, Z. Voltage Variation Performance Indices in Distribution Network. // Tehnicki vjesnik-Technical Gazette. 18, 4(2011), pp. 547-551.

[10] IEEE Standard 519-1992, Recommended Practices and Requirements for Harmonic Control in Electrical Power Systems, The Institute of Electrical and Electronics Engineers, 1993.

[11] European standard EN 50160 Voltage characteristics of electricity supplied by public distribution systems, CENELEC TC 8X, 2006

[12] Katic, N. Benefits of Smart Grid Solutions in Open Electricity Markets. // Acta Polytechnica Hungarica. 10, 2(2013), pp. 49-68.

[13] Rogowski, W.; Steinhaus, W. Die Messung der Magnetischen Spannung. // Arch. Elektrotech. 1, 4(1912), pp. 141-150. DOI: 10.1007/BF01656479

[14] Ward, D. A. Measurement of current using Rogowski coils. // Instrumentation in the Electrical Supply Industry, IEEE Colloquium on (Proc.). (1993), pp. 1-3.

[15] Zhang, Ming; Li, Kaicheng; He, Shunfan; Wang, Jun. Design and Test of a New High-Current Electronic Current Transformer with a Rogowski Coil. // Metrol. Meas. Syst. XXI, 1(2014), pp. 121-132. DOI: 10.2478/mms-2014-0012

[16] Pjevalica, V.; Vujicic, V. Measurement of Nonsinusoidal Electrical Power and Energy. // Electronics. 5, 1-2(2001), pp. 111-113.

[17] Pjevalica, V.; Vujicic, V. Further Generalization of the Low-Frequency True-RMS Instrument. // IEEE Trans. on Instr. Meas. 59, 3(2010), pp. 736-744. DOl: 10.1109/TIM.2009.2030874

[18] Comic, D.; Milovancev, S.; Vujicic, V. A New Approach to Voltage Measurements in Power Systems. $/ / 9^{\text {th }}$ Int. Conf., Electrical Power Quality and Utilization, Barcelona, Oct. 2007. DOI: 10.1109/epqu.2007.4424218

[19] Antic, B. M.; Mitrovic, Z. L.; Vujicic, V. V. A Method for Harmonic Measurement of Real Power Grid Signals with Frequency Drift using Instruments with Internally Generated Reference Frequency. // Meas. Sci. Rev. 12, 6(2012). DOI: 10.2478/v10048-012-0038-1

[20] Vujicic, B; Sokola, M; Mitrovic, Z.; Santrac, B.; Vujicic, V. Coreless current measurement transducer and instrument for distorted and noisy currents. // $13^{\text {th }}$ European Conference on Power Electronics and Applications, 2009. EPE '09, 2009, pp. 1-9.

[21] Santrac, B. M.; Sokola, M. A.; Mitrovic, Z.; Zupunski, I.; Vujicic, V. A Novel Method for Stochastic Measurement of Harmonics at Low Signal-to-Noise Ratio. // IEEE Trans. on Instr. Meas. 58, 10(2009), pp. 3434-3441. DOI: 10.1109/TIM.2009.2017661

[22] Mitrovic, Z. A Phase Angle Standard. // Measurement Science and Technology. 15(2004), pp. 559-564. DOl: 10.1088/0957-0233/15/3/008

[23] Mitrovic, Z.; Milovancev, S.; Zupunski, I. A Precision Power Amplifier for Calibration Systems. // Measurement Science and Technology. 20, 6(2009), pp. 1-3. DOI: 10.1088/0957-0233/20/6/067001

\section{Authors' addresses}

Zoran Mitrović, Professor PhD

University of Novi Sad,

Faculty of Technical Sciences,

Trg Dositeja Obradovića 6 ,

21000 Novi Sad, Serbia

E-mail: zoranmit@uns.ac.rs

Dušan Čomić, MSc

EPS Elektrovojvodina,

Bulevar oslobođenja 100,

21000 Novi Sad, Serbia

E-mail: Dusan.Comic@ns.ev.rs

Slobodan Milovančev, Professor PhD

University of Novi Sad,

Faculty of Technical Sciences,

Trg Dositeja Obradovića 6 ,

21000 Novi Sad, Serbia

E-mail: batamilo@uns.ac.rs

Dragan Pejić, Assistant Professor PhD

University of Novi Sad,

Faculty of Technical Sciences,

Trg Dositeja Obradovića 6,

21000 Novi Sad, Serbia

E-mail: pejicdra@uns.ac.rs 